\title{
The Analysis of the Influences of Student's Narcissistic Personality Traits to Negative Mentoring Experiences
}

\author{
Zheng Li \\ School of Public Affairs, University of Science and Technology of China, Heifei, China \\ Email: 10943444@qq.com
}

Received 10 February 2015; accepted 8 March 2015; published 11 March 2015

Copyright (C) 2015 by author and Scientific Research Publishing Inc.

This work is licensed under the Creative Commons Attribution International License (CC BY). http://creativecommons.org/licenses/by/4.0/

(c) (i) Open Access

\begin{abstract}
Narcissistic personality traits have been extensively studied in foreign countries. However, there is little domestic related research on it. We use a questionnaire survey to analyze the correlations of narcissistic level and negative mentoring experiences. This study will examine the effects of graduate students' narcissistic personality traits and negative mentoring experiences that graduate students have experienced. 301 graduate students of a 985 university have participated in the survey. Finally, we found that the level of narcissism has a positive impact on the degree of the negative mentoring experiences they experience. In the five dimensions of negative mentoring experiences, level of narcissism has the greatest positive effect on distancing behavior than other dimensions, while the minimal positive effect on general dysfunction. In addition, we also discuss the relationship between the level of narcissism and the quality of mentor student relationship, intention to maintain the relationship. We hope that this paper could provide valuable reference for improving the quality of graduate education.
\end{abstract}

\section{Keywords}

Narcissistic Personality, Negative Mentoring Experiences, Alienated Behavior

\section{Introduction}

The father of modern management-Peter F. Drucker said in the writings: "Digging the cave in the right place is more important than digging the cave in a right way.” Obviously, doing the right thing is more important than doing things correctly. To graduates, how to identify the right things depends on the mentor's right guidance. Therefore, mentors play a pivotal role in the growth of graduate students. Although most guiding experience 
play an active role, some inappropriate guiding experience exist, such as being extremely harsh, asking for too much, also hindering the development of students, and bringing a negative experience to students.

Current researches on the negative experiences are concentrated on the mentor's personality, style and approaches of guidance, but rarely from the perspective of students to be analyzed. Graduate experience as a party to the guidance, their personality traits will affect its guiding experience. Graduates, with aggressive personality traits, tend to have the characteristics of thinking more, good communication skills, strong insight and others (Yuan, 2012). They are better at asking questions, and able to understand the instructor's introduction and guidance more quickly so as to achieve sound guidance. And other graduates, with narcissistic personality traits, because of their arrogance, and other special privileged guiding nature, may have unrealistic expectations to the mentors, and thus feel a negative experience. In recent years, narcissistic personality traits have got a lot of attention in foreign countries, resulting in a large number of valuable research results, while domestic narcissism personality trait researches are still relatively small, especially the research on narcissistic personality traits of graduates for guiding experience.

In view of this, this paper will analyze the impact of narcissistic personality traits on the graduates' negative experiences of guidance in depth, expecting to provide a valuable basis for the reform of mentoring from a new perspective, thereby contributing to improving the quality of graduate education.

\section{Theoretical Basis and Research Hypothesis}

\subsection{Narcissistic Personality and Negative Guidance Experiences}

\subsubsection{Features of Narcissistic Personality}

The concept of narcissism comes from an ancient Greek mythology, in which a handsome boy named Narcissus crushed himself because of his reflection in the water, staring at it all day and refusing to leave, and eventually haggard to death, he turned to daffodils which is a kind of flower, named after Narcissus. But there is not still a unified, rigorous definition (Zhao, 2007). In the clinical level, the narcissistic personality is seen as personality disorder. DSM-IV (1994) described the narcissistic personality disorder as a general pattern of exaggerated behavior needing admiration, with diverse manifestations (Huang, 2004). In non-clinical areas, narcissism is generally considered to be a long-term in nature, in the form of diversification, integrated personality structure, and namely individuals focus on and indulge themselves too much. APA (1968) described narcissism as "the psychological interest concentrating on oneself." Narcissists tend to have the responsibility to accept a successful outcome, and refuse the condemnation for the unsuccessful results.

Narcissism is never the same as "self-love", "self-esteem", not absolutely a derogatory term either (Chen, 2010). Huang Shuang, a domestic scholar gives 9 narcissistic features, such as being jealous of others, behaving arrogantly. If someone had presented at least five points, he would have been diagnosed as narcissistic personality disorder, but only when the symptoms reached extreme performance, considered as pathological narcissism (Huang, 2005), while reflecting as a personality trait when these behaviors were performed at a weaker level. Lasch, social critics, believes that the narcissistic personality is ubiquitous among normal people.

Generally speaking, narcissistic personality traits include showing extreme self-absorption and self-centralism; performing self-expansion and exaggeration; indulging in unlimited success, power; and needing much attention and admiration; behaving with manipulation and utilization; presenting a strong sense of privilege, superiority upon ordinary people; being lack of empathy and compassion and so on.

\subsubsection{Negative Guiding Experience}

Mentoring relationship is generally described as a relationship of development that an experienced person (mentor) provides career support and (or) personal support to another person (apprentice) (Kram, 1986). From this description, the guiding experience of "professional support", "personal support" should be positive. However, researchers have mentioned earlier that guidance sometimes produce bad effects (Chao, 1997; Scandura, 1992). For example, some mentors may be over harsh, fastidious to the students, or set a high standard for the students, which may not be conducive to the development of students (Levinson, 1978; Darling, 1985).

Other scholars pointed out that some deviant behavior in the workplace, such as sexual harassment, provocations and insults, deceit and bullying behavior, etc., may also occur in mentoring relationship (Eby \& McManus, 2004). Robinson summed up 45 kinds of abnormal behaviors in the workplace, many also occurring in guiding relations (Robinson \& Bennett, 1995). Eby, with his teammates, found that there were five cases which are most 
likely to cause negative guiding experience: instructors and students' attitudes, values and beliefs are different; mentors are alienated to students; mentors manipulate students, or lack of professional guiding experience; function of overall guidance loses effect. On this basis, they developed a scale for measuring teachers and students' levels to perceive the negative guiding experience, whose scale has five dimensions, namely, "different characters of two sides," “alienating behavior”, “manipulation”, "lack of professional guiding experience” and “failure of overall function”.

\subsection{The Impact of Narcissistic Level on Negative Guiding Experience}

The individuals with a higher narcissistic level have a natural sense of superiority, hoping to get more attention and recognition from the mentor during the guiding process, but in reality it often fails, which makes it easy for them to give a negative evaluation of the relevant experience, exposing their discontent. That, in turn, leads to a negative evaluation from mentors to students, and the students will face more negative guiding experience (Eby et al., 2004). Thus, we speculate that the students' narcissistic level has a positive impact on the negative guiding experience. The following contents will present specific analysis on the five dimensions of the negative guiding experience:

\subsubsection{The Impact of Narcissism on Perceiving Different Characters of Two Sides}

Different characters of both sides show that the graduates and instructors have different backgrounds, habits, attitudes, values, beliefs, and different principles of dealing with people and things.

The individuals with a higher narcissistic level have a sense of superiority, considering that he has the absolute right values, beliefs, and often different from ordinary people because of his unique charm, reluctant to agree with others, lack of empathy, and self-focused. Therefore, they do not tend to identify themselves similar attitudes, beliefs with the mentor, perceive much stronger personality difference. Therefore, they have much more perception of negative guiding experience caused by different personalities in mentoring relationships. Therefore, the following hypothesis can be made:

Hypothesis I: The narcissistic level of students has a positive impact upon the different personalities from mentors they perceive.

\subsubsection{The Impact of Narcissism on Perceiving the Alienating Behavior}

Alienating behavior shows that the instructors keep little contact with the graduates, not enough concentration on guiding work and draw little attention to the health and development of the students (Mathieu, 2013).

Students, with narcissistic personality traits, think that they should take it for granted to get preference, special treatment and guidance from instructors, have unreasonable expectations, hoping to get mentors' frequent care and concern for their own development to promote academy, career, and even in all respects, to remove obstacles to their future. But in fact, it is impossible to achieve that. Therefore, people with high levels of narcissism will think that the mentors are alienated to themselves, not being concerned about their development, or giving them timely help. Thus the following hypothesis can be made:

Hypothesis II: Students’ narcissistic level has a positive influence on their perception of the instructor's alienating behavior.

\subsubsection{The Impact of Narcissism on Perceiving Manipulation}

Manipulation shows that the mentor asks graduates to do some chores or private things (Ames, 2006), acquiring more achievements than he deserves, belittling the students' working ability.

People, with narcissistic personality traits, behave manipulatively, but are particularly sensitive and averse to someone's slightly manipulative assignment. They will feel offensive once perceiving something done without any benefit to themselves, and they think it unreasonable to help the mentor to do some trivial. People who have this trait often exaggerate their achievements and ability, meanwhile, ignore the achievements of others and dedication, and therefore, they are more likely to feel unequal and think that they should have got more in return and others should not when the achievement fruits are being distributed. Thus the hypothesis can be made:

Hypothesis III: Students' narcissistic level has a positive influence on their perception of the instructor's manipulation. 
2.2.4. The Impact of Narcissism on Perceiving Lack of Professional Guiding Experience

Lack of the professional guiding experience shows that the mentors are short of professional knowledge, not good at interaction, and can not give enough help to the graduates (Mathieu, 2013).

People, with narcissistic personality traits, have strong sense of superiority beyond the ordinary, think that their communication, working ability are better than others, more easily perceive deficiencies of others, over expect people around them to pursue perfection. Thus, the individual, with higher level of narcissism, perceive their tutor's lack of professional guiding experience much more strongly. Thus the hypothesis can be made:

Hypothesis IV: Students' narcissistic level has a positive influence on their perception of the instructor's lack of the professional guiding experience.

\subsubsection{The Impact of Narcissism on Perceiving Failure of Overall Function}

Failure of overall function shows that the mentor can not absorb in and have a negative attitude towards guiding work, very harsh to members in his team (Allen et al., 2004).

The individuals, with higher level of narcissism, addicted to unlimited success, power, are more sensitive to the negative attitude of others, slight friction, often easier to feel offended, and make a more intense reaction (Eby et al., 2004). Therefore, they can perceive more bad aspects in the guiding process, more inclined to feel failure of the overall function. Thus the hypothesis can be made:

Hypothesis V: Students narcissistic level has a positive influence on their perception of failure of the overall function.

Generally, students' level of narcissism has a positive impact on each dimension of the negative guiding experience. The higher the level of narcissism is, the more negative guiding experience they can perceive. Thus, the hypothesis can be made:

Hypothesis VI: Students' level of narcissism has a positive impact on each dimension of the negative guiding experience.

\section{The Questionnaire Design}

\subsection{Sample Description}

To explore the impact of narcissistic personality traits on the negative guiding experience, we designed a related questionnaire, mainly focusing on the graduates of grade two and upon majoring science and engineering and liberal arts in a 985-project university. 360 pieces of questionnaire were distributed in various postgraduate laboratories and study rooms, a total of 301 pieces in all recovered questionnaires found to comply with the study requirements (Allen, 1997).

\subsection{The Scale of Narcissistic Personality Trait}

In this paper, the measurement on characteristics of narcissistic personality adopted the most commonly used scales-NPI (Narcissistic Personality inventory), Raskin first developed narcissistic personality scale NPI-40 in 1988. And in 2006, Ames, with his teammates, make some amendments on this basis, achieving the scale NPI16 with less narcissistic personality test items, and by five researches concerned, verified its good discriminate validity and predictive validity. The study found that NPI-40 and NPI-16 significantly had positive correlation $(r=0.90)$, and NPI-16 has a good internal and external consistency. In this paper, NPI-16 Scale, Cronbach's alpha values (referred to as $\alpha$ value) of 0.63 , five Likert-type scale are adopted, from "very inconsistent" to "very much in line” recorded from 1 to 5 points. The higher score is, the higher level of narcissism tested can be indicated.

\subsection{The Scale of Negative Guiding Experience}

This paper studies the impact of narcissistic personality trait on every dimension of negative guiding experience, its overall level and five dimensions in detail, thereby affecting the overall level of negative guiding experience (Ragins, 1999).

This paper adopts the negative guiding scale compiled Eby and his group, the scale factor loadings greater than $0.56, \alpha 0.97$. There are five major items used to measure the degree of both sides' different characters, 
alienating behavior, manipulative behavior, lack of professional experience and failure of overall function (Zhou, 1999).

\subsubsection{Different Characters of Both Sides}

This subscale has nine test items, including different work habits, understandings of effective work and study, and personalities, etc. $\alpha$ value 0.94 .

\subsubsection{Alienating Behavior}

This subscale has seven test items, including "the mentor seems too busy to see me due to much trivial," "the mentor only devote to his own development," "When I touch and communicate with the mentor, he is always absent-minded" etc. and $\alpha 0.93$.

\subsubsection{Manipulative Behavior}

There are 11 test items in this graph, including "the tutor has the intention to intervene my occupational development", "the tutor asks me to deal with his chores", "when I obtained the achievement, the tutor got much more than what he deserved" etc. The alpha value is 0.96 .

\subsubsection{Lacking Professional Experience in Guiding}

There are 7 test items in this graph, including "my tutor lacks necessary professional knowledge", "my tutor can not fill my knowledge gap", "my tutor does not have enough skills of communication, not good at interaction." etc. The alpha value is 0.94 .

\subsubsection{Failure of Overall Function}

There are 8 test items in this graph, including "the tutor hold a negative attitude in handling some work", "the tutor tend to bring his personal problems or emotion into work or scientific research", "the tutor will stop his or her work due to insignificant matter". The alpha value is 0.95 .

All of the test items are suitable for Likert type magnitude scale, the respondents are required to choose between "quite nonconformity" and "quite accord with the condition", respectively scoring 1 to 5 points, the higher the points, the more the touching of negative mentoring experience.

\subsection{Relationship Maintaining Intention Subscales}

This graph comes from the adaptation of scales of Cammann and other people, in order to measure the intention of the graduates to maintain current mentoring relationship.

The alpha value is 0.96 . There are 3 test items in this subscale, "I am willing to maintain current mentoring relationship", "I hope current mentoring relationship can be maintained for a long time" and "I love present mentoring relationship, hoping to maintain such relationship". The respondents are required to choose between "quite nonconformity" and "quite accord with the condition", respectively scoring 1 to 5 points, the higher the scores, the higher the willing to maintain mentoring relationship.

\subsection{Relationship Quality Subscales}

This thesis adopts Allen's development scale to measure the quality of mentoring relationship (Yang, 2010), there are 5 test items in this scale, for example, "the mentoring relationship between my tutor and I is high-efficient, and so on. According to the research data, the alpha value is 0.95. Allen and other people's research data is 0.92, Allen, Eby et al. (2004) develops this scale to measure the relationship quality of tutor mentoring sensed by the tutor. According to confirmatory factor analysis, the alpha value is 0.85 . This scale is also suitable for the measurement of relationship quality sensed by the graduates. The respondents are required to choose between "quite nonconformity" and "quite accord with the condition", respectively scoring 1 to 5 points, the higher the scores, the higher the sense of the quality of mentoring quality. This paper also adopts several variables related with dependent variables as control variables. These control variables include: age (under 23 scores 1 point, and by this analogy), gender (male scores 1 point, female scores 2 points), education background (graduate scores 1 point, doctor's scores 2 points). 


\section{The Empirical Analysis Results}

\subsection{Descriptive Analysis}

We use PASW Statistics 16 to conduct descriptive analysis on the distribution of the education background, gender and age of the graduates, just as what Table 1 shows. The descriptive statistics analysis result of other variables are just as what Table 2 shows, including the information of the minimum, maximum, average of every variable (Zhaohui, 1999).

According to Table 1, we can conclude that the samples of graduates are more than the doctors, boys are more than girls. This basically accord with the condition of this school. The age is also basically accord with the reality.

\subsection{Reliability Analysis}

In order to make sure the scientific of research design as well as the methods, along with the validity of research conclusion, before the related analysis, we must conduct validity test on the collected data. On general, if the Cronbach's alpha value is over 0.7 , it proves that the credibility of the scale is relatively good. There are 69 test items in this paper's scale; validity test is conducted on the collected data. We find that credibility alpha value is 0.96; therefore this scale had sound credibility.

\subsection{Related Analysis}

This paper checks whether correlations exists between every variable by related analysis, the results are as follows.

Just as what Table 3 shows, we can draw following conclusion:

Table 1. The descriptive statistical result of latent variable.

\begin{tabular}{|c|c|c|c|c|}
\hline Variable & Index & Frequency & Percentage & Grand total \\
\hline \multirow{2}{*}{ Education background } & Graduate & 191 & $63.46 \%$ & $63.46 \%$ \\
\hline & Doctor & 110 & $36.54 \%$ & $100 \%$ \\
\hline \multirow{2}{*}{ Gender } & Male & 261 & $86.71 \%$ & $86.71 \%$ \\
\hline & Female & 40 & $13.29 \%$ & $100 \%$ \\
\hline \multirow{4}{*}{ Age } & Under 23 & 99 & $32.89 \%$ & $32.89 \%$ \\
\hline & 23 to 26 & 151 & $50.17 \%$ & $83.06 \%$ \\
\hline & 26 to 29 & 50 & $16.61 \%$ & $99.67 \%$ \\
\hline & Above 29 & 1 & $0.33 \%$ & $100 \%$ \\
\hline
\end{tabular}

Table 2. The descriptive statistical result of continuous variable.

\begin{tabular}{|c|c|c|c|c|}
\hline Variable & Minimum & Maximum & Average & Standard deviation \\
\hline Level of narcissism & 1.00 & 5.00 & 3.217 & 0.7354 \\
\hline $\begin{array}{l}\text { Intention of maintaining } \\
\text { relationship }\end{array}$ & 1.00 & 5.00 & 2.060 & 1.1070 \\
\hline Quality of relation & 1.00 & 5.00 & 3.340 & 0.9240 \\
\hline Negative mentoring experience & 1.00 & 5.00 & 2.471 & 0.7847 \\
\hline $\begin{array}{l}\text { Difference of characteristics of } \\
\text { both parties }\end{array}$ & 1.00 & 5.00 & 3.115 & 0.8590 \\
\hline Alienated behavior & 1.00 & 5.00 & 2.622 & 0.9945 \\
\hline Manipulated & 1.00 & 5.00 & 2.435 & 1.0172 \\
\hline $\begin{array}{l}\text { Lacking professional guiding } \\
\text { experience }\end{array}$ & 1.00 & 5.00 & 2.333 & 0.9927 \\
\hline Failure of overall function & 1.00 & 5.00 & 2.283 & 0.8240 \\
\hline
\end{tabular}


Table 3. The correlation analysis between every variable.

\begin{tabular}{|c|c|c|c|c|c|c|c|c|c|c|c|c|}
\hline Related analysis & 1 & 2 & 3 & 4 & 5 & 6 & 7 & 8 & 9 & 10 & 11 & 12 \\
\hline Level of narcissism & 1 & & & & & & & & & & & \\
\hline $\begin{array}{l}\text { Negative mentoring } \\
\text { experience }\end{array}$ & $0.569^{* *}$ & 1 & & & & & & & & & & \\
\hline $\begin{array}{l}\text { Difference of } \\
\text { characteristics of } \\
\text { both parties }\end{array}$ & $0.459^{* *}$ & $0.608^{* *}$ & 1 & & & & & & & & & \\
\hline Alienated behavior & $0.560^{* *}$ & $0.890^{* *}$ & $0.523^{* *}$ & 1 & & & & & & & & \\
\hline $\begin{array}{l}\text { Manipulated } \\
\text { behavior }\end{array}$ & $0.416^{* *}$ & $0.855^{* *}$ & $0.276^{* *}$ & $0.740^{* *}$ & 1 & & & & & & & \\
\hline $\begin{array}{l}\text { Lacking professional } \\
\text { guiding experience }\end{array}$ & $0.488^{* *}$ & $0.864^{* *}$ & $0.326^{* *}$ & $0.680^{* *}$ & $0.812^{* *}$ & 1 & & & & & & \\
\hline $\begin{array}{l}\text { Failure of overall } \\
\text { function }\end{array}$ & $0.377^{* *}$ & $0.822^{* *}$ & $0.312^{* *}$ & $0.664^{* *}$ & $0.727^{* *}$ & $0.751^{* *}$ & 1 & & & & & \\
\hline $\begin{array}{l}\text { Intention to maintain } \\
\text { relation }\end{array}$ & $-0.479^{* *}$ & $-0.796^{* *}$ & $-0.451^{* *}$ & $-0.716^{* *}$ & $-0.695^{* *}$ & $-0.699^{* *}$ & $-0.665^{* *}$ & 1 & & & & \\
\hline Quality of relation & $-0.381^{* *}$ & $-0.671^{* *}$ & $-0.481^{* *}$ & $-0.584^{* *}$ & $-0.594^{* *}$ & $-0.613^{* *}$ & $-0.561^{* *}$ & $0.578^{* *}$ & 1 & & & \\
\hline Gender & $-0.117^{*}$ & -0.084 & $-0.166^{* *}$ & -0.057 & -0.034 & $-0.116^{*}$ & -0.074 & 0.062 & $0.125^{*}$ & 1 & & \\
\hline Age & 0.058 & $0.135^{*}$ & $-0.119^{*}$ & $0.146^{*}$ & $0.307^{* *}$ & $0.235^{* *}$ & $0.159^{* *}$ & $-0.144^{*}$ & $-0.217^{* *}$ & -0.019 & 1 & \\
\hline Education & -0.109 & -0.008 & $-0.279^{* *}$ & -0.002 & $0.186^{* *}$ & $0.129^{*}$ & $0.166^{* *}$ & 0.056 & -0.104 & 0.027 & $\begin{array}{l}0.027 \\
0.499^{* *}\end{array}$ & 1 \\
\hline
\end{tabular}

Note: $\mathrm{N}=301 .{ }^{*}$ Significant correlation at 0.05 level (double side). ${ }^{* *}$ Significant correlation at 0.01 level (double side).

1) Level of narcissism has positive correlation with difference of characteristic of both parties, alienated behavior, manipulated behavior, lack of professional guidance and failure of overall function. Therefore, the assumption 1 to 5 are all proved.

2) Level of narcissism has positive correlations with negative guiding experience ( $\mathrm{r}=0.569, p=0.01$ ), the assumption 6 is proved, the higher the level of students' narcissism, the more the sense of negative guiding experience;

3) Level of narcissism has negative correlation with relation maintaining $(r=-0.479, p=0.01)$ that is, that is, the higher the level of narcissism, the lower the intention of maintaining current relation;

4) Level of narcissism has negative correlation with quality of relation( $\mathrm{r}=-0.381, p=0.01)$ that is, the higher the level of narcissism, the lower the sense of the quality of the sense of guiding relation;

5) negative guiding experience has negative correlation with relationship maintaining $(r=-0.796, p=0.01)$, that is, the more the sense of negative guiding experience, the less the students' intention of maintaining current relation;

6) negative guiding experience has negative correlation with quality of relation ( $\mathrm{r}=-0.671, p=0.01)$, that is, the more the sense of negative guiding experience, the lower the quality of students' sense of mentoring relation;

7) level of narcissism and gender have evident negative correlation at level $0.05(\mathrm{r}=-117, p=0.05$, that is, boys' level of narcissism is a little higher than girls;

8) Correlation between narcissism and age and education background is not obvious.

\section{Conclusion}

1) The higher the level of students' narcissism, the more the sense of negative guiding experience, the lower the quality of the sense of mentoring relation, the less the intention of maintaining current guiding relation. This accords with the assumption in this paper.

2) The level of narcissism has positive correlation with negative guiding experience and other 5 dimensions. Level of narcissism has the highest correlation index with alienated behavior $(r=0.560)$. In other words, 
alienated behavior sensed by the students is the most frequent one in 5 dimensions of negative guiding experience, this accords with Eby (2000) and other people's result of empirical study. Alienated behavior has the highest negative correlation of intention of maintaining relation $(r=-0.716)$. The overlook of the tutors is the most frequent experience sensed by the students. Does this result prove that students all consider that tutor ignores them? Or do students consider that that are not able to get the response of the tutor when they are in need of help? Allen and other people's (1997) study on tutor's motivation of different guiding activities and Ragin's study (1999) on potent cost and profit of mentoring relation can provide us clear knowledge on these problems. Those problems are worthy of our attention and further research.

3) Negative mentoring experience and relationship quality have evident negative correlation with intention of maintaining relation. In other words, those negative experiences exert a negative effect on mentoring relation. The increase of negative effect will decrease the relationship satisfaction. Low level of mentoring relationship can not be maintained for a long time. Zhou Wenhui pointed out in his paper, the tutor's academic level, ways of guiding are the most important factors of affecting the relationship between tutors and graduates. From the data of graph 3, we can draw a conclusion that in the 5 dimensions of negative guiding experience, quality of relationship and lacking of mentoring experience have the highest negative correlation $(r=-0.613)$, which also prove this point. Therefore, we can aim at improving tutors' academic level, providing them professional training, so as to improve the quality of relationship.

4) Level of narcissism and gender show evident negative correlation at level $0.05(\mathrm{r}=-0.117)$, in other words, boys have higher level of narcissism than girls, this result conforms to the research result of scholars Yang Yajie and Zhouhui as well as that of many people who study narcissism in this field. Perhaps just as Yang Yajie mentioned "Male and female receive unequal respect due to their gender in society". In Chinese society, we require men should own sense of responsibility, strong-willed, achieve success in career, which will lead to men lost in the illusion of success and power, presenting the behavior or attitude of cocky and arrogant. Therefore, female got the highest score in the measurement of level of narcissism.

\section{Limitations and Future Expectations}

This paper makes an empirical study on the influences of student's narcissistic personality traits to negative mentoring experiences in the form of questionnaire, proving the hypothesis provided, achieving unexpected results and worth further study. However, because of limitations on knowledge and ability, the limitations of this paper also existed.

1) This paper only focus on the influences of student's narcissistic personality traits to negative mentoring experiences, but not putting forward constructive suggestions, we can make a theoretical study on this aspect.

2) This paper does not research the process of the being of narcissistic personality traits as well as the performance and change in mentoring relationship, and we can make a theoretical study on this aspect.

3) The future research can make an examination and predication on the tutors' and students' traits who are prone to be affected by negative mentoring experiences. Certainly, we should consider the universality of negative mentoring experience; reference may be made to two-spot relationship, therefore making a widespread and deep analysis on it, so as to making contributions to improving the graduates' quality of education.

\section{References}

Allen, T. D., Eby, L. T., Poteet, M. L., Lentz, E., \& Lima, L. (2004). Outcomes Associated with Mentoring Proteges: A MetaAnalysis. Journal of Applied Psychology, 89, 127-136. http://dx.doi.org/10.1037/0021-9010.89.1.127

Allen, T. D., Poteet, M. L., \& Burroughs, S. M. (1997). The Mentor's Perspective: A Qualitative Inquiry and Future Research Agenda. Journal of Vocational Behavior, 51, 70-89. http://dx.doi.org/10.1006/jvbe.1997.1596

Ames, D. R. (2006).The NPI-16 as a Short Measure of Narcissism. Journal of Research in Personality, 40, 440-450. http://dx.doi.org/10.1016/j.jrp.2005.03.002

Chao, G. T. (1997). Mentoring Phases and Outcomes. Journal of Vocational Behavior, 51, 15-28. http://dx.doi.org/10.1006/jvbe.1997.1591

Chen, Z. (2010). The Related Study on Narcissism Personality Significance Level and Mental Health of University Students. Journal of An Hui Science and Technology University, 24, 119-124; 2005, 55, 72-75.

Darling, L. W. (1985). What to Do about Toxic Mentors. The Journal of Nursing Research, 15, 43-44. 
Eby, L. T., \& McManus, S. E. (2000). The Protégés’ Perspective Regarding Negative Mentoring Experiences: The Development of a Taxonomy. Journal of Vocational Behavior, 57, 1-21. http://dx.doi.org/10.1006/jvbe.1999.1726

Eby, L. T., \& McManus, S. E. (2004). The Protégé’s Role in Negative Mentoring Experiences. Journal of Vocational Behavior, 65, 255-275. http://dx.doi.org/10.1016/j.jvb.2003.07.001

Eby, L. T., Buits, M., Lockwood, A., \& Simon, S. A. (2004). Protégés’ Negative Mentoring Experiences Construct Development and Nomological Validation. Personnel Psychology, 57, 411-447.

Huang, L. (2004). The Related Study on Narcissism Personality and Mental Health of University Students. Chongqing: Southwest Normal University.

Huang, S. (2005). The Origin and Treatment of Narcissism Personality Traits Obstacle. Chinese Special Education, 55, $72-$ 75.

Kram, K. E. (1986). Mentoring in the Workplace. Career Development in Organizations, 160-201.

Levinson, D. J., Darrow, D., Levinson, M., Klein, E. B., \& McKee, B. (1978). Seasons of a Man's Life. New York: Academic Press.

Mathieu, C. (2013). Personality and Job Satisfaction: The Role of Narcissism. Personality and Individual Differences, 55, 650-654. http://dx.doi.org/10.1016/j.paid.2013.05.012

Ragins, B. R., \& Scandura, T. A. (1999). Burden or Blessing? Expected Costs and Benefits of Being a Mentor. Journal of Organizational Behavior, 20, 493-509.

Robinson, S. L. \& Bennett, R. J. (1995). A Typology of Deviant Workplace Behaviors: A Multidimensional Scaling Study. Academy of Management Journal, 38, 555-572. http://dx.doi.org/10.2307/256693

Scandura, T. A. (1992). Mentorship and Career Mobility: An Empirical Investigation. Journal of Organizational Behavior, 13, 169-174. http://dx.doi.org/10.1002/job.4030130206

Yang, Y. J. (2010). Questionnaire Construction and Theocratical Exploration of Personality Disorder of University Students. Health of Chinese School, 31, 799-801.

Yuan, M. (2012). The Effect of Aggressive Personality Traits on Work Performance: The Mediation of Leader-Member Relation. Shanghai: Shanghai Jiao Tong University.

Zhao, J. (2007). The Research Progress of Narcissism. Magazine of Psychiatry, 20, 52-57.

Zhou, W. H. (2010). The Research on the Current Situation of the Relationship between Graduates and Tutors in Chinese University. Degree and Graduate Education, 9, 7-14. 